\title{
The Combined Role of P- and E-Selectins in Atherosclerosis
}

\author{
Zhao Ming Dong, ${ }^{\star \ddagger}$ Susan M. Chapman, ${ }^{\star}$ Allison A. Brown, ${ }^{\star}$ Paul S. Frenette, ${ }^{\S}$ Richard O. Hynes,, and Denisa D. Wagner ${ }^{\star \ddagger}$ \\ *Center for Blood Research, ${ }^{\star}$ Department of Pathology, and ${ }^{\S}$ Department of Medicine, Harvard Medical School, Boston, Massachusetts \\ 02115; "Howard Hughes Medical Institute, Center for Cancer Research, Department of Biology, Massachusetts Institute of Technology, \\ Cambridge, Massachusetts 02139
}

\begin{abstract}
P- and E-selectins are adhesion molecules mediating the first step in leukocyte extravasation. Because their function in leukocyte adhesion is overlapping, we hypothesized that there might be a combined effect of these selectins on the development of atherosclerotic lesions. We bred P- and E-selectin-double-deficient mice onto the low-density lipoprotein receptor (LDLR)-deficient background (LDLR-I$\left.\mathrm{P} / \mathrm{E}-I_{-}\right)$and compared lesion development in these mice to that in mice wild type for both selectins (LDLR $-/-\mathrm{P} / \mathrm{E}+/+$ ). After $8 \mathrm{wk}$ on atherogenic diet, the LDLR-I- P/E-Imice developed fatty streaks in the aortic sinus that were five times smaller than those in LDLR $-/-\mathrm{P} / \mathrm{E}+/+$ mice. The density of macrophages in the fatty streaks was comparable between LDLR $-I-\mathrm{P} / \mathrm{E}+I+$ and $\mathrm{LDLR}-I-\mathrm{P} / \mathrm{E}-I-$ mice. After 22 wk on the diet, the lesions spread throughout the aorta but this process was delayed in LDLR $-I-\mathrm{P} / \mathrm{E}-I-$ mice. At 37 wk on diet, the lesions progressed to the fibrous plaque stage in both genotypes. However, the lesions in the aortic sinus in LDLR $-I-\mathrm{P} / \mathrm{E}-/-$ mice were $40 \%$ smaller and less calcified than those of $\mathrm{LDLR}-I-\mathrm{P} / \mathrm{E}+I+$ mice. Our results suggest that $\mathrm{P}$ - and E-selectins together play an important role in both early and advanced stages of atherosclerotic lesion development. (J. Clin. Invest. 1998. 102:145152.) Key words: leukocyte adhesion - animal model for atherosclerosis • macrophage $\cdot$ smooth muscle cells $\bullet$ lipofuscin
\end{abstract}

\section{Introduction}

Adhesion of circulating leukocytes, especially monocytes, to the endothelial lining is an early event in atherosclerosis. The active stages of atherosclerosis are marked by the extensive infiltration of these monocytes through the endothelium into the arterial intima (1). It is now well documented that leukocyte and endothelial adhesion molecules play an important role in the emigration of leukocytes from the blood into foci of inflammation (2-3), and similar processes could be at work in atherosclerosis. However, it is unclear which cell adhesion molecules are important in atherogenesis.

Address correspondence to Denisa D. Wagner, Center for Blood Research, Harvard Medical School, 800 Huntington Avenue, Boston, MA 02115. Phone: 617-278-3344; FAX: 617-278-3368.

Received for publication 5 February 1997 and accepted in revised form 30 April 1998.

J. Clin. Invest.

(C) The American Society for Clinical Investigation, Inc. 0021-9738/98/07/0145/08 \$2.00

Volume 102, Number 1, July 1998, 145-152

http://www.jci.org
Leukocyte rolling along the endothelial surface is the first step in leukocyte adhesion to endothelial cells. Multiple studies indicate that leukocyte rolling is mediated by the selectin family of adhesion receptors and their carbohydrate ligands (4). L-selectin is constitutively expressed on the surfaces of most leukocytes. E-selectin is found only on endothelial cells stimulated by inflammatory cytokines. P-selectin is rapidly released from storage granules in activated platelets and endothelial cells. The generation of selectin-deficient mice has confirmed the role of selectins in the rolling of blood cells and provided evidence indicating that there is an overlapping function of these selectins in the regulation of inflammatory processes (5-9). In our previous study, P-selectin-deficient ( $\mathrm{P}-/-$ ) mice were bred onto a low density lipoprotein receptor (LDLR $)^{1}$-deficient background that represents an animal model of familial hypercholesterolemia (10). We found that absence of P-selectin partially reduced fatty streak formation but did not significantly affect lesion progression to fibrous plaque stage in LDLR-deficient mice (11). These results suggested that other selectins such as E-selectin may be able to promote monocyte recruitment in the LDLR $-/-\mathrm{P}-/-$ mice in late stages of lesion development. To investigate this possibility, we have generated a line of $\mathrm{LDLR}-/-\mathrm{P} / \mathrm{E}-/-$ mice, and compared lesion development in these mice to LDLR-/mice lacking just $\mathrm{P}$-selectin or wild type for both selectins.

\section{Methods}

Mice, genotype analysis, and diets. P- and E-selectin double-deficient $(\mathrm{P} / \mathrm{E}-1-)$ mice were generated in our laboratory and were on a mixed C57BL/6J $\times 129 \mathrm{~Sv}$ background (7). LDLR-deficient mice (LDLR-/-) were provided by Joachim Herz at University of Texas Southwestern Medical Center (Dallas, TX) and were also on a mixed C57BL/6J $\times 129$ Sv background (10). Because the selectin family of genes is clustered on chromosome 1 within $300 \mathrm{~kb}$, we were able to produce mice deficient in LDLR (the gene is located on chromosome 9) and both selectins (LDLR $-/-\mathrm{P} / \mathrm{E}-/-$ ) by mating LDLR $-/-$ mice to $\mathrm{P} / \mathrm{E}-1-$ mice. Littermates from the $\mathrm{F} 2$ generation of this intercross were genotyped by PCR analysis and used to establish LDLR $-/-\mathrm{P} / \mathrm{E}-/-$ matings and LDLR $-/-\mathrm{P} / \mathrm{E}+/+$ matings. The progeny of these matings were used in our study. PCR analysis was performed for genotyping for selectins (7) and LDLR (12).

Before starting on an atherogenic diet, mice of all genotypes were maintained on a standard low fat mouse chow containing $5 \%$ fat (wt/wt) (Prolab 3000; PMI Feeds, St. Louis, MO). When they were 5-7-wk-old, mice were placed on an atherogenic diet for indicated lengths of time. The atherogenic diet (ICN Biomedicals; Aurora, $\mathrm{OH}$ ) contained $1.23 \%$ (wt/wt) cholesterol, $17.84 \%$ (wt/wt) butter, $0.98 \%(w t / w t)$ corn oil, and $0.48 \%(w t / w t)$ sodium cholate.

Cholesterol determination. Mice were fasted overnight before transport to the laboratory and blood was collected through the retroorbital venous plexus. Cholesterol concentrations in total plasma

1. Abbreviations used in this paper: LDLR, low density lipoprotein receptor; VCAM-1, vascular cell adhesion molecule-1. 
were determined using an enzymatic assay according to the manufacturer's instructions (Cholesterol kit 352-50, Sigma Chemical Co.).

Quantitation of aortic sinus lesions. The sections containing aortic sinus lesions were prepared as described (11). Four consecutive $10-\mu \mathrm{m}$ sections were collected for each slide. 10 slides were made from each animal. Odd-numbered slides were stained with oil red-O and hematoxylin, counterstained with light green, and examined for lesion size and calcium deposits. Even-numbered slides were kept for histological and immunohistochemical analysis. Five sections, each $80 \mu \mathrm{m}$ apart, were scored for each animal without knowledge of the genotype. The area of the lesion was measured with a Leica Q500MC image analysis program (Leica Inc., Deerfield, IL). Values reported represent the mean lesion area from five sections for each animal.

Quantitation of lesions in entire aorta. Mice were perfused with $4 \%$ paraformaldehyde for 15-20 min, and aortae were collected between the subclavian and ilial branches, placed in $4 \%$ paraformaldehyde for $4-6 \mathrm{~h}$, followed by placement in $30 \%$ sucrose (wt/vol) for $2-3 \mathrm{~d}$, and then stored in $10 \%$ formalin for later analysis. The entire aortae were stained with Sudan IV, as described (11). After staining, aortae were opened longitudinally and mounted on slides using glycerol gelatin. For quantitation of Sudan IV-stained surface area, mounted aortae were visualized through a JVL TK-1280U color video camera into a Leica Q500MC image analysis program. Percentage of area covered by lesion was determined by Sudan IV-stained area divided by total aorta area.

Histological analysis. Calcium deposits were identified by the hematoxylin stain, as described (13). Odd-numbered slides stained with oil red-O, hematoxylin, and light green were examined by light microscopy for presence of calcification. A total of 20 sections (five slides) from the aortic sinus were examined for each animal. Mice were considered positive if calcium deposits were observed in one or more sections.

To assess lipofuscin accumulation on the surface of the aortic valve leaflets, unstained even-numbered slides were examined by light microscopy for the presence of yellow-brown lipofuscin pigment deposits (14). The presence of lipofuscin in any 1 of 20 sections (five slides) defined the mouse as lipofuscin-positive.

To quantitate cell density in the 8-wk lesions, the four sections on slide No. 6 for each mouse were stained with hematoxylin and numbers of the blue cell nuclei in the lesion area were counted through a light microscopy. Cell density was expressed as the number of cell nuclei per square millimeter of atherosclerotic lesion area.

Immunohistochemical analysis. To identify macrophages and $\mathrm{T}$ cells in aortic sinus lesions from mice on atherogenic diet for $8 \mathrm{wk}$, frozen sections $(10-\mu \mathrm{m}$-thick) were fixed in cold acetone for $5 \mathrm{~min}$, and then incubated with avidin-blocking solution followed by biotinblocking solution for $30 \mathrm{~min}$ each. Endogenous peroxidase activity was blocked by incubating slides in a solution of $3 \%$ hydrogen peroxide for $5 \mathrm{~min}$. Slides were then incubated with a biotin-conjugated anti-Mac-1 antibody (No. 01712D, dilution 1:10; PharMingen, San Diego, CA) for identification of macrophages, or a biotin-conjugated anti-CD3 antibody (No. 01082A, dilution 1:25; PharMingen) for identification of $\mathrm{T}$ cells. Antibodies were visualized by an avidin/biotin peroxidase-linked detection system from Vector Laboratories (Burlingame, CA). Antibody was omitted from the control sections. Detection of intracellular TNF- $\alpha$ on frozen sections of 8 -wk lesions was performed as described (15). A rat anti-mouse TNF- $\alpha$ monoclonal antibody (No. 18131D, dilution 1:4; PharMingen) was used. To quantitate smooth muscle cells in 22- and 37-wk lesions, two sections on slide No. 8 for each mouse were stained with a mouse monoclonal antibody against human $\alpha$-actin directly coupled to horseradish peroxidase (No. U7033, dilution 1:2; DAKO Corp., Carpinteria, CA) as described (11), and the other two sections on the same slide were incubated either with diluted normal mouse serum or without the antibody as controls. The $\alpha$-actin positive area of the lesion was measured with a Leica Q500MC image analysis program. Percentage of lesion area positive for $\alpha$-actin was determined by $\alpha$-actin positive area of the lesion divided by total atherosclerotic lesion area.
Statistical analysis. Data are presented as mean \pm SEM. Student's $t$ test and chi-square analyses were performed using software for the MacIntosh.

\section{Results}

Generation of mice with combined $P$ - and E-selectin and LDLR deficiencies. To study the role of P- and E-selectins in atherosclerotic lesion development, we bred $\mathrm{P} / \mathrm{E}-1-$ mice with $\mathrm{LDLR}-/-$ mice to generate $\mathrm{LDLR}-/-\mathrm{P} / \mathrm{E}+/+$ and LDLR $-/-\mathrm{P} / \mathrm{E}-/-$ mice. Like the $\mathrm{P} / \mathrm{E}-/-$ mice that present some degree of immunodeficiency (7), LDLR-/- P/E-/mice suffered from a cutaneous infection starting at $\sim 16 \mathrm{wk}$ of age; this occurred at a higher percentage in the female mice. To rule out infection as a factor affecting atherosclerotic lesion development in LDLR-/- $\mathrm{P} / \mathrm{E}-/-$ mice, in the long-term experiments (diet for 22 or $37 \mathrm{wk}$ ) we only collected data from male mice without skin infections. LDLR $-/-\mathrm{P} / \mathrm{E}+/+$ and LDLR $-/-\mathrm{P} / \mathrm{E}-/-$ male mice responded similarly to the atherogenic diet, as demonstrated by similar body weight and comparable levels of cholesterol in the blood at all three observation times (Table I). Because most older female LDLR-/$\mathrm{P} / \mathrm{E}-/-$ mice developed skin infections, we were only able to collect data from females on the diet for $8 \mathrm{wk}$; again, there were no statistically significant differences between the two genotypes in body weight and total plasma cholesterol (data not shown).

$P$ - and E-selectin deficiency inhibits formation of atherosclerotic lesions in the proximal aorta. The proximal aorta is particularly prone to the development of intimal lesions in mouse models of atherosclerosis, and the extent of lesions in the proximal aorta has been shown to correlate with that of the entire aorta in LDLR - /- mice (16). To examine the effect of P- and E-selectin deficiency on the development of atherosclerotic lesions in the proximal aorta, mean lesion areas were measured in oil red-O-stained tissue sections from LDLR-/- P/E $+/+$ and LDLR-/- P/E-/- mice on atherogenic diet for 8-37 wk. Previously, we reported that, after 8 wk on the diet, the lesion areas in LDLR $-/-\mathrm{P}-/-$ male mice are twofold smaller than those in LDLR $-/-\mathrm{P}+/+$ male mice, but the lesion areas in females are similar for both genotypes (11). Surprisingly, after

Table I. Body Weight and Total Plasma Cholesterol in LDLR-deficient Male Mice on Atherogenic Diet

\begin{tabular}{lccc}
\hline Diet length & Genotype & Body weight & Cholesterol \\
\hline$w k$ & & $g /$ mouse & $m g / d l$ \\
8 & P/E-selectin $+/+$ & $30.2 \pm 0.91(15)$ & $2109 \pm 116(15)$ \\
& P/E-selectin $-/-$ & $29.5 \pm 0.75(15)$ & $1810 \pm 148(15)$ \\
22 & P/E-selectin +/+ & $31.7 \pm 1.03(16)$ & $1769 \pm 148(15)$ \\
& P/E-selectin $-/-$ & $30.8 \pm 1.15(17)$ & $1490 \pm 143(17)$ \\
37 & P/E-selectin +/+ & $32.3 \pm 1.25(17)$ & $1716 \pm 181(17)$ \\
& P/E-selectin $-/-$ & $34.4 \pm 2.32(11)$ & $1823 \pm 216(8)$
\end{tabular}

Mice were fed high fat/cholesterol diet for 8,22 , or $37 \mathrm{wk}$, at which time plasma was collected and analyzed for total cholesterol. The values represent the mean \pm SEM. The values in parentheses represent the numbers of animals evaluated. There are no statistically significant differences between the two groups in body weight and total plasma cholesterol. 


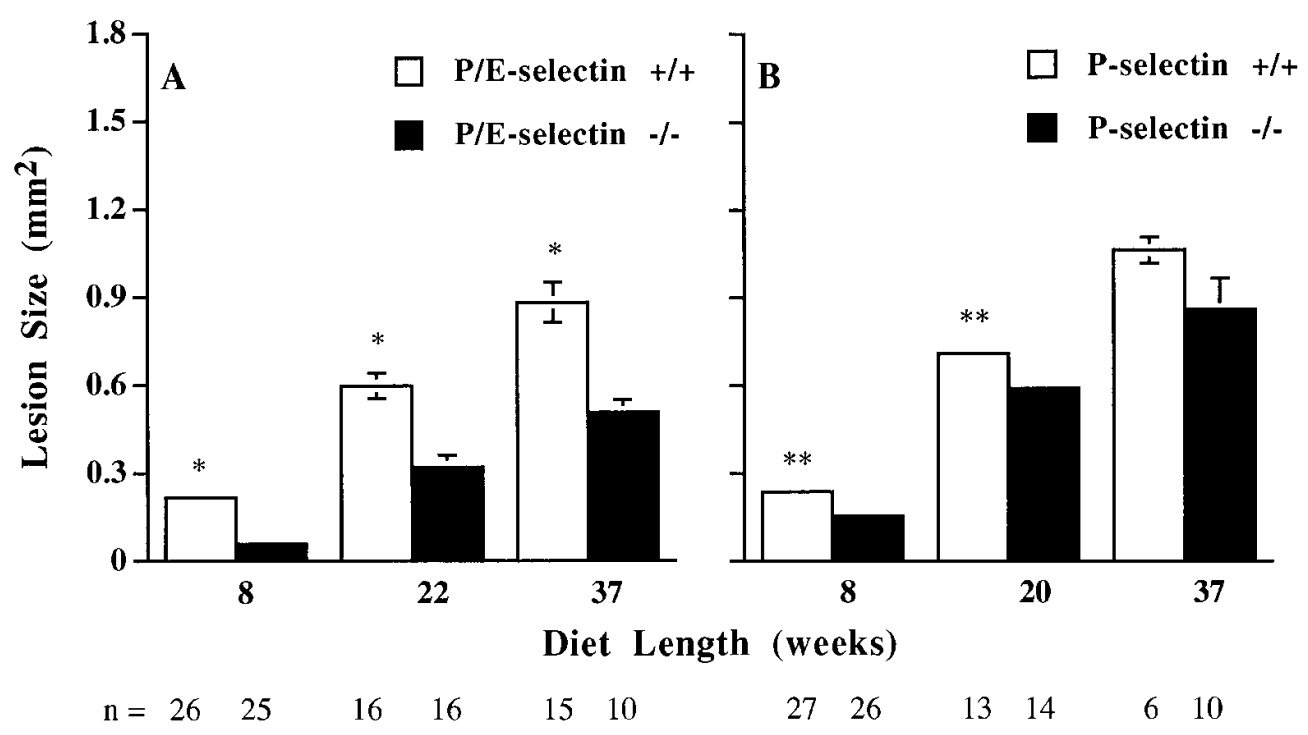

Figure 1. Atherosclerotic lesion size in LDLR-deficient mice with and without selectins. 5-7-wk-old mice were fed an atherogenic diet for 8-37 wk. Sections of aortic sinus were stained with oil red-O, hematoxylin, and light green, and the area of the lesion was measured. Values reported represent the mean lesion area from five sections for each animal. $(A)$ Comparison of lesion size in LDLR $-/-\mathrm{P} / \mathrm{E}+/+$ and LDLR $-/-\mathrm{P} / \mathrm{E}-/-$ mice. At

$8 \mathrm{wk}$, both male and female mice were combined. At 22 or 37 wk, only male mice were used. (B) Comparison of lesion size in LDLR $-/-\mathrm{P}+/+$ and LDLR $-/-\mathrm{P}-/-$ mice. The data were published previously (11). *(A) LDLR $-/-\mathrm{P} / \mathrm{E}+/+$ versus LDLR $-/-\mathrm{P} / \mathrm{E}-/-; P<0.0005 ; * *(B) \mathrm{LDLR}-/-\mathrm{P}+/+$ versus LDLR $-/-\mathrm{P}-/-; P<0.05$. Error bars in some columns are not shown because the corresponding SEM is too small.

8 wk on the diet, LDLR $-/-\mathrm{P} / \mathrm{E}-/-$ male mice had lesions $5.4 \times$ smaller than the LDLR $-/-\mathrm{P} / \mathrm{E}+/+$ males $(P<0.0001)$, and LDLR $-/-\mathrm{P} / \mathrm{E}-/-$ female mice had lesions $4 \times$ smaller than the LDLR $-/-\mathrm{P} / \mathrm{E}+/+$ females $(P<0.0001)$. The combined data from males and females are shown in Fig. $1 A$. Interestingly, lesions in $\mathrm{LDLR}-/-\mathrm{P} / \mathrm{E}-/-$ mice were $3.3 \times$ smaller than those in the LDLR-/- $\mathrm{P}-/-$ mice. In addition, after $8 \mathrm{wk}$ on the diet, $78 \%$ of the aortic sinus circumference in LDLR $-/-\mathrm{P} / \mathrm{E}+/+$ mice was covered by oil red-O-stained positive lesions, as compared to $57 \%$ found in LDLR-/$\mathrm{P} / \mathrm{E}-/-$ mice $(P<0.0001, n=25-26$, data not shown $)$. Therefore, $\mathrm{LDLR}-/-\mathrm{P} / \mathrm{E}-/-$ mice had more lesion-free aortic sinus surface as well as smaller lesions than did LDLR-/$\mathrm{P} / \mathrm{E}+/+$ mice.

With time on the atherogenic diet, lesions grew in both LDLR $-/-\mathrm{P} / \mathrm{E}+/+$ and LDLR-/- P/E-/ - mice (Fig. $1 A$ ). Previously, we have shown that, after $20 \mathrm{wk}$ on the diet, a slightly smaller lesion was observed in LDLR $-/-\mathrm{P}-/-$ mice as compared to LDLR $-/-\mathrm{P}+/+$ mice, and at $37 \mathrm{wk}$ the lesion size difference was no longer significant (Fig. $1 \mathrm{~B}$ ). However, after either 22 or $37 \mathrm{wk}$ on the diet, lesion size in LDLR-/$\mathrm{P} / \mathrm{E}-/-$ mice was significantly smaller than that in LDLR-/$\mathrm{P} / \mathrm{E}+/+$ mice (Fig. 1 A). Actually, LDLR $-/-\mathrm{P} / \mathrm{E}-/-$ mice on diet for $37 \mathrm{wk}$ had a comparable lesion size to LDLR-/$\mathrm{P} / \mathrm{E}+/+$ mice on diet for $22 \mathrm{wk}($ Fig. $1 A$ ), indicating that $\mathrm{P} / \mathrm{E}$ selectin deficiency could delay lesion growth in LDLR-/mice by $\sim 15 \mathrm{wk}$, even at late stages of lesion development. Unlike at $8 \mathrm{wk}$, after $22 \mathrm{wk}$, the percentage of lesion coverage on the aortic sinus circumference was similar in both LDLR-/$\mathrm{P} / \mathrm{E}+/+$ and LDLR $-/-\mathrm{P} / \mathrm{E}-/-$ mice $(\sim 90-95 \%$, data not shown).

$P$ - and E-selectin deficiency delays atherosclerotic lesion development throughout the entire aorta. The extent of atherosclerosis was also determined in a defined segment of the aorta, from the subclavian branch to the iliac bifurcation. Although, after $8 \mathrm{wk}$ on the atherogenic diet, we found no obvi- ous lesions in this segment in either mouse genotype, lesions were numerous after $22 \mathrm{wk}$ on the diet. Comparison of the percentage of surface area occupied by the lesions in mice on the diet for 22 or 37 wk showed that the lesions were significantly more extensive in LDLR $-/-\mathrm{P} / \mathrm{E}+/+$ mice relative to LDLR $-/-\mathrm{P} / \mathrm{E}-/-$ mice (Fig. 2). Consistent with the findings in the proximal aorta, after $22 \mathrm{wk}$ on the diet, the percentage of coverage in $\mathrm{LDLR}-/-\mathrm{P} / \mathrm{E}+/+$ mice was two times more than that of LDLR-/- P/E-/- mice. Similarly, LDLR-/$\mathrm{P} / \mathrm{E}-/-$ mice on diet for $37 \mathrm{wk}$ had a comparable percentage lesion coverage of the entire aorta to LDLR-/- P/E+/+ mice on diet for only $22 \mathrm{wk}$ (Fig. 2). Our results show that absence of $\mathrm{P}$ - and E-selectins in LDLR-/- mice reduced diet-induced atherosclerotic lesion progression in both the aortic sinus and the entire aorta.

Comparison of lesion composition in LDLR-/- mice with and without $P$ - and E-selectins. Lesions in LDLR-/- mice fed a high cholesterol/fat diet can progress through at least two stages. The first stage is the fatty streak, which is characterized by the presence of lipid-filled CD11b (Mac-1)-positive macrophages in the subendothelial space. The second stage is the fibrous plaque, which consists of a central acellular area of lipid (derived from necrotic foam cells) covered by a fibrous cap containing $\alpha$-actin-positive smooth muscle cells (11). In the LDLR - / - mice, fatty streak lesions begin to appear after 2 wk on the diet, but become obvious after 8 wk (Fig. 3, $A$ and $B)$. Typical fibrous plaques could be found in the LDLR-/mice on the diet for $37 \mathrm{wk}$ (Fig. 4, $A$ and $B$ ). After $22 \mathrm{wk}$ on the diet, LDLR $-/-$ mice displayed an intermediate lesion containing foam cells and spindle-shaped smooth muscle cells. We decided to further characterize the various stages of the atherosclerotic lesions through histological analysis and immunohistochemical staining and determine whether there are differences in lesion composition between LDLR $-/-\mathrm{P} / \mathrm{E}+/+$ and LDLR $-/-\mathrm{P} / \mathrm{E}-/-$ mice. We found that in 8-wk lesions of both genotypes $98-99 \%$ of cells were CD11b-positive mac- 

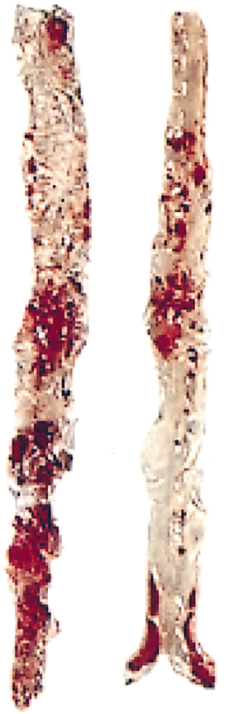

Selectin

$\mathrm{P} / \mathrm{E}+/+\quad \mathrm{P} / \mathrm{E}-/-$
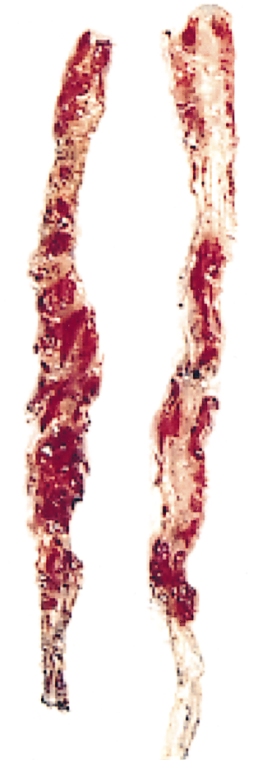

$\mathbf{P} / \mathbf{E}+/+$

$\mathrm{P} / \mathrm{E}-/-$

$51.6 \pm 5 \quad 37.7 \pm 2.4$

$<0.05$

$(n=10$ to 15$)$
Figure 2. Atherosclerotic lesions in entire aorta of LDLR-deficient mice with and without P/E-selectins. 5-7-wk-old male mice were fed an atherogenic diet for 22 or $37 \mathrm{wk}$. Aortae were collected between the subclavian and ilial branches and stained with Sudan IV. Sudan IV-stained surface area was measured by an image analysis program. Percentage of area covered by lesion (\% coverage) was calculated (Sudan IV-stained area divided by total aorta area $100 \times$ ). Representative specimens collected from both genotypes of mice on the diet for $22(A)$ and $37 \mathrm{wk}(B)$ are shown. rophages (Fig. 3, $E$ and $F$ ) and only 1-2\% were CD3-positive $\mathrm{T}$ cells (data not shown). The distributions of these cells were approximately uniform throughout 8-wk fatty streak lesions. By counting the cell nuclei per unit of lesion area, we found that there was no difference in cell density between the two genotypes of mice $\left(2,610 \pm 125 / \mathrm{mm}^{2}\right.$ in $\mathrm{LDLR}-/-\mathrm{P} / \mathrm{E}+/+$ mice versus $2,640 \pm 198 / \mathrm{mm}^{2}$ in LDLR $-/-\mathrm{P} / \mathrm{E}-/-$ mice, $P>$ $0.05, n=25-26)$. However, because lesions were smaller in the LDLR $-/-\mathrm{P} / \mathrm{E}-/-$ mice, total cell numbers per section in these mice were significantly lower than those in the LDLR-/$\mathrm{P} / \mathrm{E}+/+$ mice $(125 \pm 23$ in $\mathrm{LDLR}-/-\mathrm{P} / \mathrm{E}-/-$ mice versus $577 \pm 55$ in LDLR $-/-\mathrm{P} / \mathrm{E}+/+$ mice, $P<0.001, n=25-26)$. Furthermore, the percentage of cells that express TNF- $\alpha$ on 8 -wk lesions was similar in both genotypes of mice $(\sim 90 \%$, Fig. 3, $G$ and $H$ ). We also found that there were no differences in percent lesion area positive for $\alpha$-actin staining in both genotypes of mice after 22 or $37 \mathrm{wk}$ on diet (Table II). Our results indicate that smooth muscle cell growth in the fibrous plaque stage of lesions of LDLR $-/-\mathrm{P} / \mathrm{E}-/-$ mice still reached a normal proportion despite their smaller lesion size as compared to LDLR $-/-\mathrm{P} / \mathrm{E}+/+$ mice. However, after $37 \mathrm{wk}$ on the diet, fibrous plaque lesions in most of the LDLR $-/-\mathrm{P} / \mathrm{E}+/+$ mice had calcified; whereas calcification was rare in the lesions from LDLR - / - P/E-/- mice (Table II; Fig. 4, $C$ and $D$ ). Therefore, the absence of $\mathrm{P}$ - and E-selectin in LDLR-/- mice did delay the formation of some components of atherosclerotic lesions, such as calcification. In addition, a lower incidence of cardiac lipofuscin was observed in LDLR-/- P/E-/- mice lesions throughout the experimental period (Table II; Fig. 3, $C$ and $D)$.

\section{Discussion}

Pathogenesis of atherosclerosis is a complex process. A variety of cells, growth factors, cytokines, and vasoregulatory molecules participate in this disease (1). Here we present data showing that the endothelial selectins (P- and E-selectins), to-
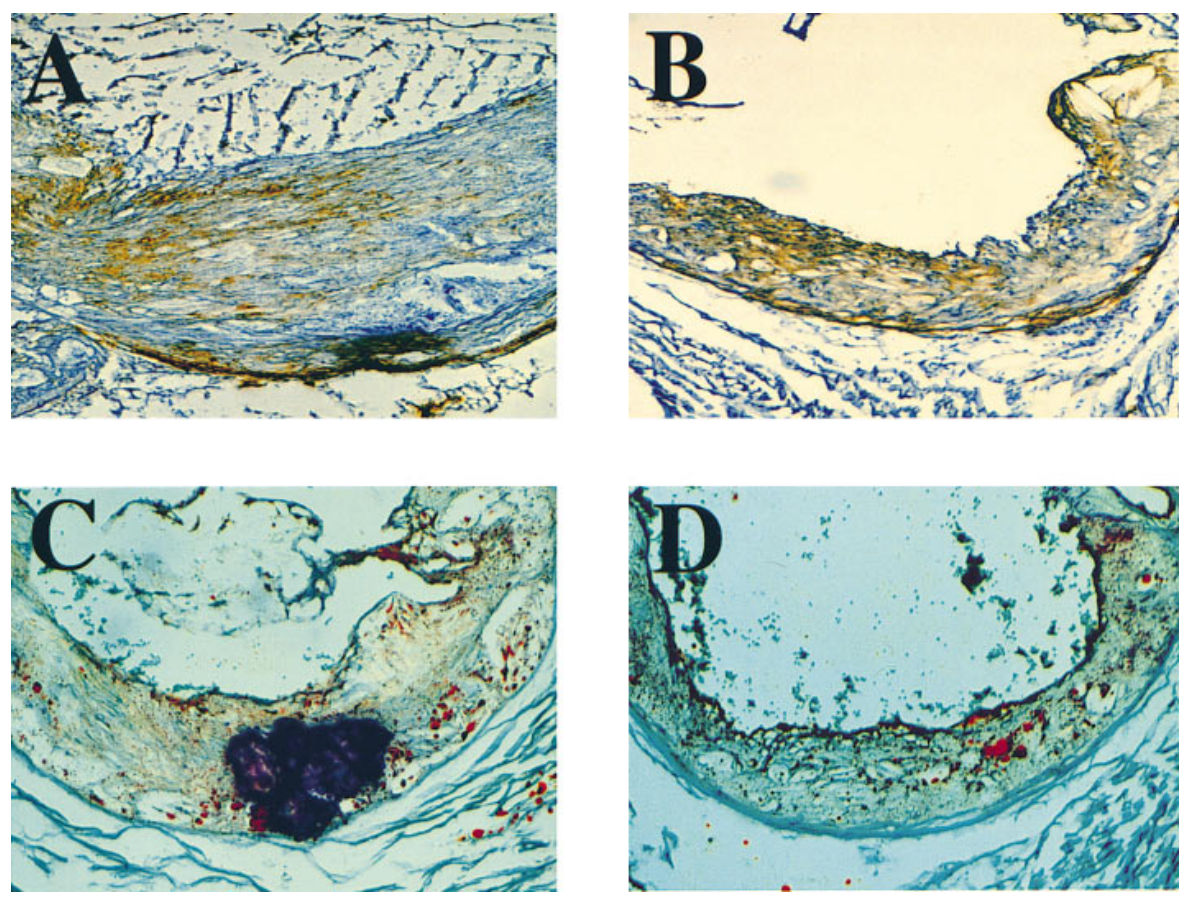

Figure 4. Histological analysis of atherosclerotic lesions in LDLR-deficient mice after $37 \mathrm{wk}$ on an atherogenic diet. Photomicrographs show fibrous plaque and calcification of aortic sinus lesion of LDLRdeficient mice with $(A$ and $C)$ and without $(B$ and $D)$ P/E-selectins. $A$ and $B$ sections were treated with a mouse monoclonal anti- $\alpha$-actin antibody visualizing smooth muscle cells in the fibrous plaque. $C$ and $D$ sections were stained with oil red-O, hematoxylin, and light green. Calcium deposit is seen as a bluish-purple mass due to hematoxylin stain in most LDLR-/- $/ \mathrm{E}+/+$ mice, but its presence is rare in LDLR $-/-$ $\mathrm{P} / \mathrm{E}-/-$ animals. Photographs were taken through $10 \times$ objective. 

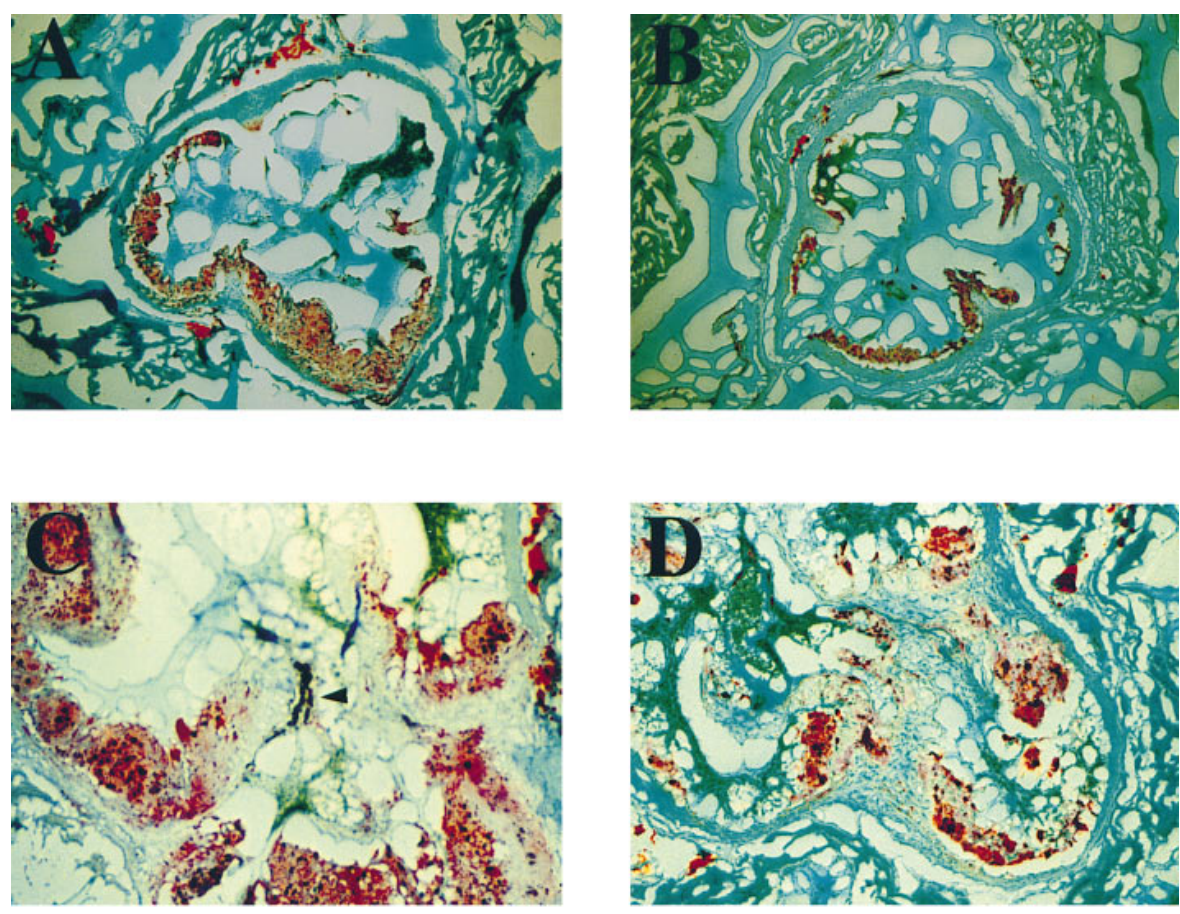

Figure 3. Histological analysis of atherosclerotic lesions in the LDLR-deficient mice after 8 wk on an atherogenic diet. Photomicrographs show fatty streak, lipofuscin deposits, macrophage and TNF- $\alpha$
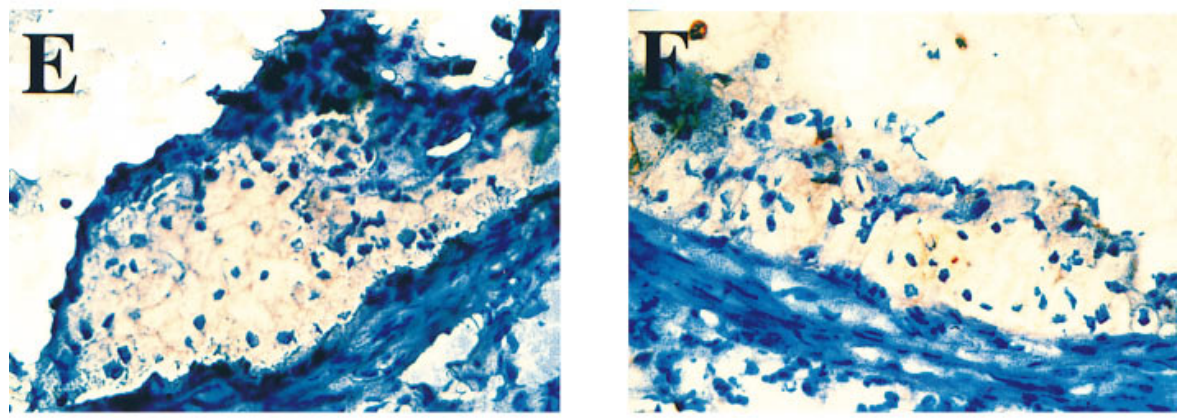
staining of aortic sinus lesions of LDLRdeficient mice with $(A, C, E$, and $G)$ and without $\mathrm{P} /$ E-selectins $(B, D, F$, and $H) . A$ and $B$ sections were stained with oil red-O, hematoxylin, and light green, showing the typical fatty streak lesions. A uniform oil red-O-positive staining pattern was observed in both genotypes of mice even though lesions in LDLR $-/-\mathrm{P} / \mathrm{E}+/+$ mice were much larger than those in LDLR - /$\mathrm{P} / \mathrm{E}-/-$ mice. $C$ and $D$ sections show yellow-brown lipofuscin pigment granules on surfaces of aortic valve leaflets from LDLR $-/-\mathrm{P} / \mathrm{E}+/+$ mice (arrowhead), but not from LDLR $-/-\mathrm{P} / \mathrm{E}-/-$ mice. $E$ and $F$ sections were stained with a rat mono-
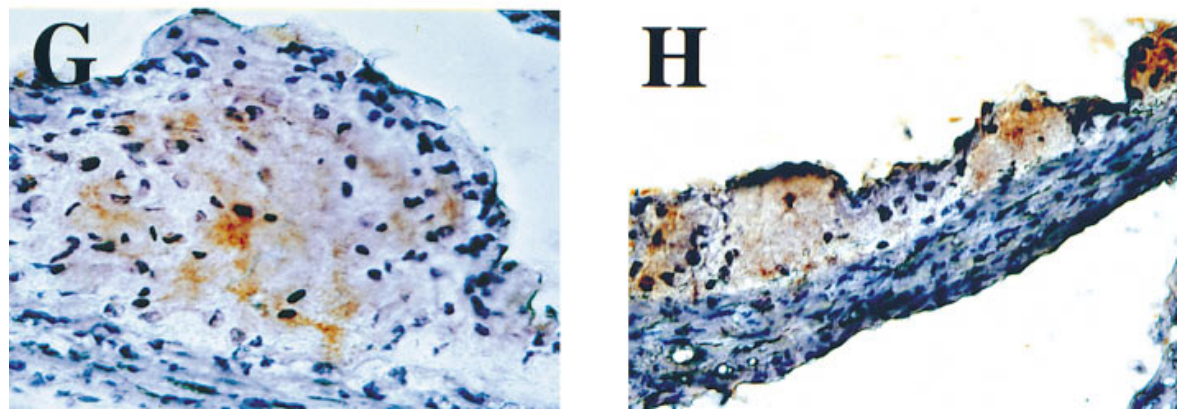
clonal antibody to Mac-1, showing fatty streaks laden with Mac-1-positive macrophages. The cell density between the two genotypes of mice was comparable. $G$ and $H$ sections were stained with a rat antimouse TNF- $\alpha$ monoclonal antibody visualizing intracellular TNF- $\alpha$. Approximately $90 \%$ cells were positive for TNF- $\alpha$ in both genotypes of mice. Photographs were taken through following objectives: $4 \times(A$ and $B), 10 \times(C$ and $D), 40 \times(E, F, G$, and $H)$.

gether, play a critical role in both early and late stages of atherosclerotic lesion development. The finding is based on the following observations. First, the size of the fatty streaks formed in the aortic sinus of LDLR-deficient mice on a high fat/cholesterol diet (atherogenic diet) for $8 \mathrm{wk}$ was two times smaller in absence of P-selectin, but was five times smaller in the absence of both P- and E-selectins. Second, the size of the fibrous plaque formed in the aortic sinus of LDLR-deficient mice on an atherogenic diet for $37 \mathrm{wk}$ was identical in the pres- ence and absence of P-selectin, but was significantly reduced by $40 \%$ when both selectins were absent (Fig. 1 ). Similarly, the area occupied by atherosclerotic lesions in the entire aorta was comparable for LDLR $-/-\mathrm{P}+/+$ and $\mathrm{LDLR}-/-\mathrm{P}-/-$ mice on the diet for $37 \mathrm{wk}$ (11) but was decreased in LDLR-/$\mathrm{P} / \mathrm{E}-/-$ mice (Fig. 2). In addition, in a preliminary study, we have found that after $8 \mathrm{wk}$ on an atherogenic diet, the size of the fatty streaks formed in the aortic sinus of LDLR-deficient mice without E-selectin (LDLR-/-E-/-) was not smaller 
Table II. Lipofuscin, Smooth Muscle Cells, and Calcification in Aortic Sinus Lesions of LDLR-deficient Mice on Atherogenic Diet

\begin{tabular}{lcccc}
\hline $\begin{array}{l}\text { Diet length } \\
\text { (wk) }\end{array}$ & Genotype & $\begin{array}{c}\text { Incidence of } \\
\text { lipofuscin* }\end{array}$ & $\begin{array}{c}\text { Lesion area } \\
\text { positive for } \\
\alpha \text {-actin }\end{array}$ & $\begin{array}{c}\text { Incidence of } \\
\text { calcification* }\end{array}$ \\
\hline \multirow{5}{*}{8} & & $\%$ & \\
\multirow{4}{*}{22} & P/E-selectin $+/+$ & $15 / 24(63 \%)$ & 0 & $0 / 24(0 \%)$ \\
& P/E-selectin $-/-$ & $0 / 25(0 \%)^{\ddagger}$ & 0 & $0 / 25(0 \%)$ \\
37 & P/E-selectin $+/+$ & $14 / 16(88 \%)$ & $20 \pm 1.4$ & $3 / 16(20 \%)$ \\
& P/E-selectin $-/-$ & $5 / 16(31 \%)^{\ddagger}$ & $23 \pm 1.5$ & $1 / 17(6 \%)^{\ddagger}$ \\
& P/E-selectin $+/+$ & $11 / 15(73 \%)$ & $31 \pm 8.8$ & $14 / 15(93 \%)$ \\
& P/E-selectin $-/-$ & $3 / 10(30 \%)^{\ddagger}$ & $30 \pm 6.1$ & $2 / 10(20 \%)^{\ddagger}$
\end{tabular}

*Fraction of lipofuscin-positive or calcification-positive mice/total number of mice in group. ${ }^{\ddagger} \mathrm{P} / \mathrm{E}-/-$ versus $\mathrm{P} / \mathrm{E}+/+$ : comparison by chi-square test, $\mathrm{x}^{2}>7.5, P<0.01$. There are no statistically significant differences in percent lesion area positive for $\alpha$-actin between the two genotypes of mice after 22 or 37 wk on diet.

than that in LDLR $-/-E+/+$ mice (data not shown). This suggests that a deficiency of E-selectin alone does not have a major protective effect on atherosclerotic lesion development.

Multiple studies have indicated that the major function of selectins is to mediate neutrophil, monocyte, lymphocyte, and platelet rolling along the venular wall and their effects in regulating inflammatory processes seem to be overlapping $(4,17)$. For example, mice lacking E-selectin display no obvious changes in the trafficking of leukocytes. However, treatment of the E-selectin-deficient animals with an anti-P-selectin antibody significantly inhibits leukocyte emigration, whereas the same treatment has no effect in wild-type mice (6). Mice lacking P-selectin present a complete absence of leukocyte rolling in exteriorized venules, whereas both P- and E-selectins have to be absent to abolish rolling under inflammatory conditions (7). Recently, it has been found that the absence of either P-selectin or E-selectin alone had no notable effect on skin wound healing, but mice deficient in both P- and E-selectins had markedly reduced recruitment of inflammatory cells and impaired closure of the wound (18). Our present results extend these studies and further confirm the importance of the inflammatory component in atherosclerosis.

Decreased atherosclerotic lesion size in LDLR-/- P/E-/mice is mainly due to a reduction in monocyte infiltration into the intima. The evidence is that, after $8 \mathrm{wk}$ on the atherogenic diet, the density of macrophages in the fatty streaks was comparable between LDLR-/- P/E+/+ and LDLR-/- P/E-/mice, but total cell numbers accumulated in the aortic sinus were five times less in $\mathrm{LDLR}-/-\mathrm{P} / \mathrm{E}-/-$ mice. It is well known that monocyte adhesion to the endothelium and migration into the intima is a crucial early event in development of atherosclerosis, and that migration continues in late stages of lesions (1). Macrophages in the subendothelium may protect against atherosclerosis by scavenging noxious materials, such as oxidized lipoproteins, but it is also hypothesized that they contribute to oxidized LDL formation and to the fibroproliferative process through secretion of numerous growth factors (1, 19). P- and E-selectin deficiency leads to a reduction in both early and late stages of atherosclerotic lesion development, indicating that under conditions that are optimal for lesion development, the net effect of the macrophage recruitment is proatherogenic. The lipofuscin data suggest that decreased macrophage infiltration into lesions in the absence of both selectins may lead to a reduction in oxidized LDL production; the lipofuscin pigment consists of terminally oxidized polyunsaturated lipid and protein complexes, and there are common pathways contributing to oxidized LDL, lipofuscin, and fatty streak development (14). Decreased oxidized LDL in lesions may result in reduction in lesion progression because oxidized LDL is known to stimulate expression of adhesion molecules on endothelium leading to additional cellular infiltration and is the main source of lipid in foam cells (1). Our results do not clarify why monocytes but not neutrophils are recruited specifically into atherosclerotic lesions. It does not appear that $\mathrm{P} / \mathrm{E}$ selectins provide the necessary clues. The absence of endothelial selectins reduces recruitment of neutrophils to inflamed peritoneum to similar extent (7), as it diminishes accumulation of monocytes in the fatty streaks. The adhesion receptors, or more likely, the chemokines and their receptors that direct the specific extravasation of monocytes into the atherosclerotic lesions are still elusive.

In vitro studies suggest that the selectins also affect monocyte function, especially in the production of proinflammatory cytokines such as TNF- $\alpha$ (20). So it is possible that absence of both selectins prevents lesion progression through modification of macrophage function in production of cytokines. In this study, we have found that most macrophages in atherosclerotic lesions of LDLR $-/-\mathrm{P} / \mathrm{E}-/-$ mice are still able to produce TNF- $\alpha$ (Fig. 3, $G$ and $H$ ). However, considering that the immunostaining method for detection of TNF- $\alpha$ used in this study is not quantitative, we still cannot exclude the possibility that individual macrophage in lesions of LDLR $-/-\mathrm{P} / \mathrm{E}-/-$ mice may produce lower amount of $\mathrm{TNF}-\alpha$, as compared to the macrophages from LDLR $-/-\mathrm{P} / \mathrm{E}+/+$ lesions. Furthermore, the fatty streaks in $\mathrm{LDLR}-/-\mathrm{P} / \mathrm{E}-/-$ mice also progress to fibrous plaque stage and their fibrous plaque contains a similar ratio of smooth muscle cells to other lesion components, as seen in LDLR $-/-\mathrm{P} / \mathrm{E}+/+$ mice (Fig. $4, A$ and $B$; Table II). This suggests that macrophages in the lesions of LDLR-/$\mathrm{P} / \mathrm{E}-/-$ mice likely retain the ability to induce smooth muscle cell proliferation by producing growth factors such as PDGF. Therefore, we suspect that the absence of the selectins did not greatly modify macrophage function in the atherosclerotic lesions.

In terms of a mouse model for atherosclerosis, it is interesting to see that calcifications can occur in the fibrous plaque lesion in most LDLR -/- mice, even though complicated lesions characterized by thrombosis have not yet been found. Calcification of atherosclerotic lesions has been shown to contribute to atherosclerotic plaque instability and myocardial infarction in humans (19). Therefore, the finding that calcification of atherosclerotic lesions in LDLR-/- mice could be delayed in the absence of both P- and E-selectins may have important implications for designing new methods to prevent plaque rupture. The mechanism(s) responsible for decreased calcification in LDLR $-/-\mathrm{P} / \mathrm{E}-/-$ mice is not clear. We suspect that it is due to a smaller lesion size in the $\mathrm{LDLR}-/-\mathrm{P} / \mathrm{E}-/-$ mice, as presence of calcifications seems to correlate with lesion size (Table II).

Atherosclerotic lesions still form in LDLR-/- P/E-/- 
mice, suggesting that other adhesion molecules such as vascular cell adhesion molecule-1 (VCAM-1) and L-selectin may be mediating monocyte rolling, leading to the development of atherosclerosis in these animals. VCAM-1 has been found to be expressed on endothelium before macrophage accumulation in dietary hypercholesterolemic and Watanabe heritable hyperlipidemic rabbit models of atherosclerosis (21-22). This protein on the surface of endothelial cells interacts with the $\beta 1$ integrin very late antigen-4, which is expressed mainly by mononuclear leukocytes (23). VCAM-1/very late antigen-4 pathway has been shown to mediate both rolling and firm adhesion in leukocyte transendothelial migration (24-25). L-selectin is constitutively expressed on the surface of most leukocytes. It has been shown that L-selectin mediates monocyte attachment to activated aortic endothelium (26). Because mice deficient in all three selectins (P-, E-, and L-selectins) have been recently generated (27), their combined role in atherosclerosis could be investigated.

Accumulated evidence, including our present study, supports the notion that monocyte-derived macrophages play a key role in atherogenesis $(1,28-29)$. Finding means of controlling macrophage participation in atherogenesis could be critical in modifying lesion progression. There are many potential sites that could be targeted. These include monocyte transendothelial migration, where both $\mathrm{P}$ - and E-selectins are possible target molecules as suggested by this study, as well as the processes of monocyte differentiation into macrophage, and macrophage uptake of modified lipoprotein particles. At present, it is unclear which site(s) should be targeted to get better results for inhibiting atherosclerotic lesion progression with fewer adverse effects. The effect of blocking monocyte differentiation into macrophage on the development of atherosclerosis was analyzed using mice with the op mutation (28). The mutation affects the gene-encoding macrophage colony-stimulating factor and leads to monocytopenia and decreased tissue macrophages. Atherosclerotic lesions in ApoE-deficient mice with op mutation were one-seventh the size of lesions in ApoE-deficient mice and did not progress to the fibroproliferative stage. But these double-mutant mice have two to three times more cholesterol in their blood than do the ApoE-deficient mice (28). In contrast, mice lacking the endothelial selectins have increased levels of blood monocytes (7) and their cholesterol levels are not affected by the mutation (Table I). The handicap of a long-term treatment inhibiting the selectins is that it might render the patients more susceptible to infections (7). However, it is encouraging that spontaneous skin infection occuring in $\mathrm{P} / \mathrm{E}-/-$ mice can be prevented with oral antibiotics (7). In addition to selectins, inhibition of the intercellular adhesion molecule-1/ $\beta 2$ integrin pathway of adhesion may also protect against atherosclerosis. C57BL/6 mice mutant in the intercellular adhesion molecule- 1 or $\beta_{2}$ integrin gene develop $50-75 \%$ smaller fatty streaks, when fed atherogenic diet (30). However, a long-term treatment inhibiting these adhesion receptors may cause obesity in the patients (31).

Both P- and E-selectins have been found on endothelial surfaces overlying atherosclerotic lesions in humans (32-33). Recently, E-selectin polymorphism was reported to be associated with human atherosclerosis (34). The resulting alteration enhances binding capacity of E-selectin to its ligands (35), and individuals possessing this polymorphism appear to have a higher risk for early severe atherosclerosis (34). These results, combined with our present study, lead us to suspect that the endothelial selectins may also play an important role in human atherosclerosis.

\section{Acknowledgments}

We are grateful to Lesley Cowan for help with preparation of the manuscript.

The work was supported by National Institutes of Health grants HL-53756 (D.D. Wagner) and P01-HL-41484 (R.O. Hynes). Z.M. Dong was supported by a NIH fellowship grant HL09869. S.M. Chapman and A.A. Brown were supported by a grant from Genetics Institute. R.O. Hynes is an investigator of the Howard Hughes Medical Institute. P.S. Frenette is a fellow of the Medical Research Council of Canada. The care of the experimental mice was in accordance with the guidelines of the Center for Blood Research.

\section{References}

1. Ross, R. 1993. The pathogenesis of atherosclerosis: a perspective for the 1990s. Nature. 362:801-809.

2. Bevilacqua, M.P., R.M. Nelson, G. Mannori, and O. Cecconi. 1994. Endothelial-leukocyte adhesion molecules in human disease. Annu. Rev. Med. 45: 361-378.

3. Carlos, T.M., and J.M. Harlan. 1994. Leukocyte-endothelial adhesion molecules. Blood. 84:2068-2101.

4. Frenette, P.S., and D.D. Wagner. 1997. Insights into selectin function from knockout mice. Thromb. Haemostasis. 78:60-64.

5. Mayadas, T.N., R.C. Johnson, H. Rayburn, R.O. Hynes, and D.D. Wagner. 1993. Leukocyte rolling and extravasation are severely compromised in P-selectin-deficient mice. Cell. 74:541-554.

6. Labow, M.A., C.R. Norton, J.M. Rumberger, K.M. Lombard-Gillooly, D.J. Shuster, J. Hubbard, R. Bertko, P.A. Knaack, R.W. Terry, M.L. Harbison et al. 1994. Characterization of E-selectin-deficient mice: demonstration of overlapping function of the endothelial selectins. Immunity. 1:709-720.

7. Frenette, P.S., T.N. Mayadas, H. Rayburn, R.O. Hynes, and D.D. Wagner. 1996. Susceptibility to infection and altered hematopoiesis in mice deficient in both P- and E-selectins. Cell. 84:563-574.

8. Bullard, D.C., E.J. Kunkel, H. Kubo, M.J. Hicks, I. Lorenzo, N.A. Doyle, C.M. Doerschuk, K. Ley, and A.L. Beaudet. 1996. Infectious susceptibility and severe deficiency of leukocyte rolling and recruitment in E-selectin and P-selectin double mutant mice. J. Exp. Med. 183:2329-2336.

9. Staite, N.D., J.M. Justen, L.M. Sly, A.L. Beaudet, and D.C. Bullard. 1996. Inhibition of delayed-type contact hypersensitivity in mice deficient in both E-selectin and P-selectin. Blood. 88:2973-2979.

10. Ishibashi, S., M.S. Brown, J.L. Goldstein, R.D. Gerard, R.E. Hammer, and J. Herz. 1993. Hypercholesterolemia in low density lipoprotein receptor knockout mice and its reversal by adenovirus-mediated gene delivery. J. Clin. Invest. 92:883-893.

11. Johnson, R.C., S.M. Chapman, Z.M. Dong, J.M. Ordovas, T.N. Mayadas, J. Herz, R.O. Hynes, E.J. Schaefer, and D.D. Wagner. 1997. Absence of P-selectin delays fatty streak formation in mice. J. Clin. Invest. 99:1037-1043.

12. Shimada, M., S. Ishibashi, T. Inaba, H. Yagyu, K. Harada, J.I. Osuga, K. Ohashi, Y. Yazaki, and N. Yamada. 1996. Suppression of diet-induced atherosclerosis in low density lipoprotein receptor knockout mice overexpressing lipoprotein lipase. Proc. Natl. Acad. Sci. USA. 93:7242-7246.

13. Qiao, J.H., P.Z. Xie, M.C. Fishbein, J. Kreuzer, T.A. Drake, L.L. Demer, and A.J. Lusis. 1994. Pathology of atheromatous lesions in inbred and genetically engineered mice: genetic determination of arterial calcification. Arterioscler. Thromb. 14:1480-1497.

14. Qiao, J.H., C.L. Welch, P.Z. Xie, M.C. Fishbein, and A.J. Lusis. 1993. Involvement of the tyrosinase gene in the deposition of cardiac lipofuscin in mice: association with aortic fatty streak development. J. Clin. Invest. 92:23862393.

15. Litton, M.J., B. Sander, E. Murphy, A. O'Garra, and J.S. Abrams. 1994. Early expression of cytokines in lymph nodes after treatment in vivo with Staphylococcus enterotoxin B. J. Immunol. Methods. 175:47-58.

16. Tangirala, R.K., E.R. Rubin, and W. Palinski. 1995. Quantitation of atherosclerosis in murine models: correlation between lesions in the aortic origin and in the entire aorta, and differences in the extent of lesions between sexes in LDL receptor-deficient and apolipoprotein E-deficient mice. J. Lipid. Res. 36: 2320-2328.

17. Frenette, P.S., R.C. Johnson, R.O. Hynes, and D.D. Wagner. 1995. Platelets roll on stimulated endothelium in vivo: an interaction mediated by endothelial P-selectin. Proc. Natl. Acad. Sci. USA. 92:7450-7454.

18. Subramaniam, M., S. Saffaripour, L.V.D. Water, P.S. Frenette, T.N. Mayadas, R.O. Hynes, and D.D. Wagner. 1997. Role of endothelial selectins in wound repair. Am. J. Pathol. 150:1701-1709. 
19. Berliner, J.A., M. Navab, A.M. Fogelman, J.S. Frank, L.L. Demer, P.A. Edwards, A.D. Watson, and A.J. Lusis. 1995. Atherosclerosis: basic mechanisms. Circulation. 91:2488-2496.

20. Weyrich, A.S., T.M. McIntyre, R.P. McEver, S.M. Prescott, and G.A. Zimmerman. 1995. Monocyte tethering by $\mathrm{P}$-selectin regulates monocyte chemotactic protein-1 and tumor necrosis factor- $\alpha$ secretion, signal integration and NF-кB translocation. J. Clin. Invest. 95:2297-2303.

21. Cybulsky, M.I., and M.A. Gimbrone, Jr. 1991. Endothelial expression of a mononuclear leukocyte adhesion molecule during atherosclerosis. Science. 251:788-791.

22. Li, H., M.I. Cybulsky, M.A. Gimbrone, Jr., and P. Libby. 1993. An atherogenic diet rapidly induces VCAM-1, a cytokine-regulatable mononuclear leukocyte adhesion molecules, in rabbit aortic endothelium. Arterioscler. Thromb. 13:197-204.

23. Elices, M.J., L. Osborn, Y. Takada, C. Crouse, S. Luhowskyj, M.E. Hemler, and R.R. Lobb. 1990. VCAM-1 on activated endothelium interacts with the leukocyte integrin VLA-4 at a site distinct from the VLA-4/fibronectin binding site. Cell. 60:577-584.

24. Berlin, C., R.F. Bargatze, J.J. Campbell, U.H. von Andrian, M.C. Szabo, S.R. Hasslen, R.D. Nelson, E.L. Berg, S.L. Erlandsen, and E.C. Butcher. 1995. $\alpha 4$ integrins mediate lymphocyte attachment and rolling under physiologic flow. Cell. 80:413-422.

25. Alon, R., P.D. Kassner, M.W. Carr, E.B. Finger, M.E. Hemler, and T.A. Springer. 1995. The integrin VLA-4 supports tethering and rolling in flow on VCAM-1. J. Cell Biol. 128:1243-1253.

26. Giuffre, L., A.S. Cordey, N. Monai, Y. Tardy, M. Schapira, and O. Spertini. 1997. Monocyte adhesion to activated aortic endothelium: role of L-selectin and heparan sulfate proteoglycans. J. Cell Biol. 136:945-956.
27. Robinson, S.D., P.S. Frenette, H. Rayburn, M. Cummiskey, M. UllmanCullere, D.D. Wagner, and R.O. Hynes. 1997. The generation of double and triple-deficient selectin mice. Microcirculation. 4:64a. (Abstr.).

28. Smith, J.D., E. Trogan, M. Ginsberg, C. Grigaux, J. Tian, and M. Miyata. 1995. Decreased atherosclerosis in mice deficient in both macrophage colony-stimulating factor (op) and apolipoprotein E. Proc. Natl. Acad. Sci. USA. 92:8264-8268.

29. Breslow, J.J. 1996. Mouse models of atherosclerosis. Science. 272:685-688

30. Nageh, M.F., E.T. Sandberg, K.R. Marotti, A.H. Lin, E.P. Melchior, D.C. Bullard, and A.L. Beaudet. 1997. Deficiency of inflammatory cell adhesion molecules protects against atherosclerosis in mice. Arterioscler. Thromb. Vasc. Biol. 17:1517-1520.

31. Dong, Z.M., J.C. Gutierrez-Ramos, A. Coxon, T.N. Mayadas, and D.D. Wagner. 1997. A new class of obesity genes encodes leukocyte adhesion receptors. Proc. Natl. Acad. Sci. USA. 94:7526-7530.

32. Van der Wal, A.C., P.K. Das, and A.J. Tigges. 1992. Adhesion molecules on the endothelium and mononuclear cells in human atherosclerotic lesions. Am. J. Pathol. 141:1427-1433.

33. Johnson-Tidey, R.R., J.L. McGregor, P.R. Taylor, and R.N. Poston. 1994. Increase in the adhesion molecule P-selectin in endothelium overlying atherosclerotic plaques. Am. J. Pathol. 144:952-961.

34. Wenzel, K., S. Felix, F.X. Kleber, R. Brachold, T. Menke, S. Schattke, K.L. Schulte, C. Glaser, K. Rohde, G. Baumann, and A. Speer. 1994. E-selectin polymorphism and atherosclerosis: an association study. Hum. Mol. Genet. 3 . 1935-1937.

35. Revelle, B.M., D. Scott, and P.J. Beck. 1996. Single amino acid residues in the E- and P-selectin epidermal growth factor domains can determine carbohydrate binding specificity. J. Biol. Chem. 271:16160-16170. 